\title{
A case of mixed adenoneuroendocrine carcinoma (MANEC) arising in Barrett's esophagus: literature and review
}

\author{
Tetsuro Kawazoe ${ }^{1,2}$, Hiroshi Saeki ${ }^{1 *}$, Keitaro Edahiro', Shotaro Korehisa', Daisuke Taniguchi ${ }^{1}, K^{1}$ Kensuke Kudou', \\ Ryota Nakanishi', Nobuhide Kubo ${ }^{1}$, Koji Ando ${ }^{1}$, Yuichiro Nakashima ${ }^{1}$, Eiji Oki ${ }^{1}$, Minako Fujiwara², \\ Yoshinao Oda ${ }^{2}$ and Yoshihiko Maehara ${ }^{1}$
}

\begin{abstract}
Background: Mixed adenoneuroendocrine carcinoma (MANEC) is defined as a neoplasm composed of both exocrine and endocrine carcinomas, each comprising at least 30\% of the tumor. MANEC can occur in various organs of the gastrointestinal tract, including the esophagus, stomach, and colon. We herein provide the first case report of surgically resected MANEC arising in Barrett's esophagus (BE).

Case presentation: A 70-year-old man presenting with abdominal pain was referred to our hospital. Upper endoscopy showed a type 0-lla + IIc elevated lesion adjacent to BE. According to a biopsy specimen, the elevated lesion was diagnosed as adenocarcinoma with neuroendocrine differentiation. No lymphatic or distant metastasis was detected in the preoperative examination. Laparoscopic distal esophagectomy and proximal gastrectomy were performed, and a diagnosis of MANEC in BE was determined according to the surgically resected specimen.

Conclusions: A very rare case of MANEC in BE was detected. BE can be the origin of esophageal MANEC as well as adenocarcinoma. Due to the small number of esophageal or esophagogastric MANEC cases reported, further accumulation of such cases is necessary to recommend an optimal management strategy for esophageal or esophagogastric MANEC.
\end{abstract}

Keywords: Mixed adenoneuroendocrine carcinoma (MANEC), Barrett's esophagus, Neuroendocrine tumor

\section{Background}

Since Oberndorfer first reported a case of "karzinoide" in 1907, carcinoid tumors or neuroendocrine tumors (NETs) have been debated, and the treatment strategy for these tumors has been a contentious subject [1]. In the 2010 World Health Organization (WHO) classification of neuroendocrine neoplasms in the digestive system, mixed adenoneuroendocrine carcinoma (MANEC) is defined as a neoplasm composed of both exocrine and endocrine carcinomas, each comprising at least $30 \%$ of the tumor [2]. MANECs in the gastrointestinal tract can occur in various organs such as the esophagus [3], stomach $[4,5]$, and colon [6].

\footnotetext{
*Correspondence: h-saeki@surg2.med.kyushu-u.ac.jp

${ }^{1}$ Department of Surgery and Science, Graduate School of Medical Sciences, Kyushu University, 3-1-1 Maidashi, Higashi-ku, Fukuoka 812-8582, Japan Full list of author information is available at the end of the article
}

Barrett's esophagus (BE) is an esophageal lesion exhibiting Barrett's mucosa, which is a columnar epithelial metaplasia that extends from the stomach to the esophagus, as confirmed by endoscopy. Histologically, Barrett's mucosa is characterized by the following three features: proper esophageal glands or ducts beneath the overlying columnar epithelium, squamous epithelial islets in the columnar epithelium, and double-layered lamina muscularis mucosae [7]. The malignant progression of $\mathrm{BE}$ to adenocarcinoma has been confirmed [8], and the incidence of esophageal adenocarcinoma has increased recently, especially in Western countries [9]. To the best of our knowledge, there has been only one brief case report of MANEC developing in $\mathrm{BE}$, which was resected by endoscopic submucosal dissection [10].

The incidence of esophageal carcinoma in Japan is $31.0 / 100,000$ person-years according to the National 
Cancer Center, Japan [11]. Among esophageal carcinomas, Barrett's adenocarcinoma and endocrine cell carcinoma are extremely rare, with rates of 1.1 and 0 . 2\%, respectively, among 5878 total esophageal cancer cases, according to the Comprehensive Registry of Esophageal Cancer in Japan, 2010 [12].

In this report, we present a case of MANEC that arose in histologically confirmed $\mathrm{BE}$, along with a brief literature review. We herein provide the first report of surgically resected MANEC in BE.

\section{Case presentation}

A 70-year-old man presenting with abdominal pain was referred to our hospital for further examination. He had no past history without appendicitis operated during his childhood. He claimed no family history of cancer or any genetic disorders. Laboratory data revealed no significant abnormalities. Serum levels of tumor markers such as carbohydrate antigen $19-9(25.7 \mathrm{U} / \mathrm{ml}$, normal range $<37 \mathrm{U} / \mathrm{ml}$ ) and neuron-specific enolase $(9.4 \mathrm{ng} / \mathrm{ml}$, normal range $<16.3 \mathrm{ng} / \mathrm{ml}$ ) were within the normal ranges, while the carcinoembryonic antigen level was slightly increased $(5.6 \mathrm{ng} / \mathrm{ml}$, normal range $<5.0 \mathrm{ng} / \mathrm{ml}$ ). The patient underwent upper endoscopy, which revealed BE and a type 0-IIa + IIc elevated lesion adjacent to the BE lesion (Fig. 1). The tumor biopsy specimen confirmed well to poorly differentiated adenocarcinoma with neuroendocrine differentiation. Esophagography showed a type 0-IIa + IIc elevated lesion in the left wall of the lower esophagus, with a size of $15 \mathrm{~mm}$ and an estimated depth invading into the submucosa (Fig. 2). Thoracic and abdominal contrastenhanced computed tomography revealed no evidence of an esophageal mass, lymphatic metastasis, or distant metastasis.

The patient was clinically diagnosed with adenocarcinoma developing in BE. He subsequently underwent laparoscopic distal esophagectomy, proximal gastrectomy, regional lymph node dissection, and double-tract

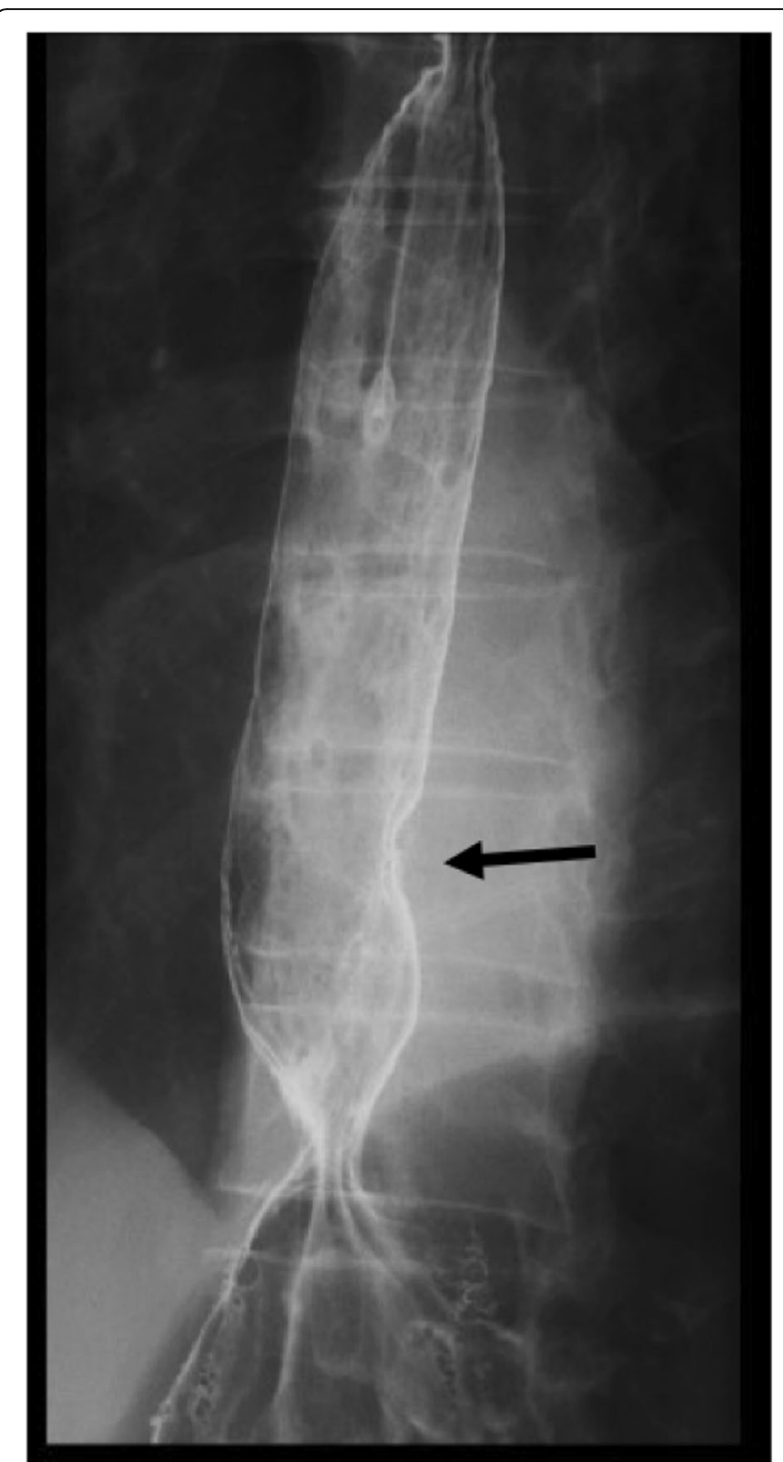

Fig. 2 Esophagography. Esophagography showed a type 0-lla + Ilc elevated lesion (15 $\mathrm{mm}$ in size) on the left wall of the lower esophagus, and the tumor exhibited arcuate change suggesting

submucosal invasion

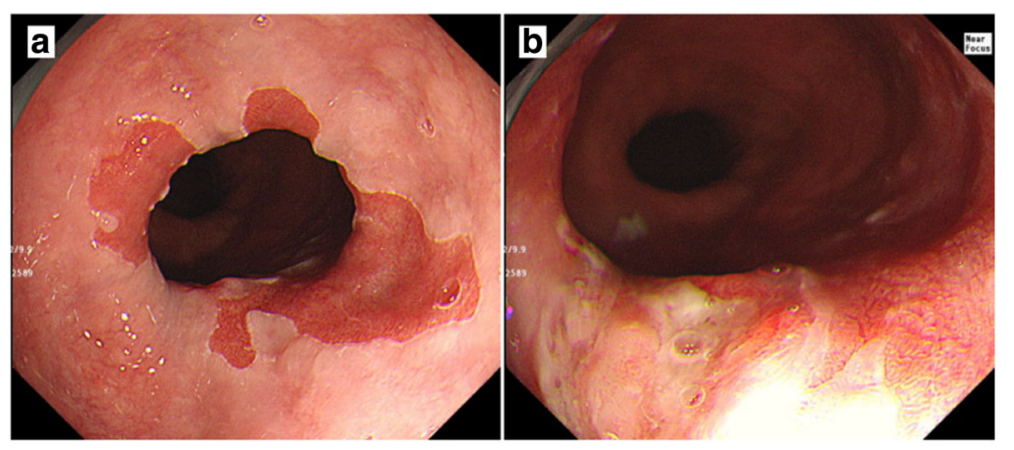

Fig. 1 Upper endoscopy. Upper endoscopy showed an elongated columnar epithelium from the squamocolumnar junction indicating BE (a) and a type 0-lla + Ilc elevated lesion adjacent to the BE lesion (b) 
reconstruction with curative intent. Intraoperative findings revealed no tumor invasion into the esophageal adventitia.

In the resected specimen, a type 0-IIa + IIc lesion measuring $25 \times 10 \mathrm{~mm}$ was macroscopically observed in the esophagogastric junction. Histological examination revealed that the neoplastic lesion was composed of well to moderately differentiated adenocarcinoma invading the submucosa and an area of proliferation of roundshaped carcinoma cells in a nested or sheeted pattern (Fig. 3). The round-shaped carcinoma cells contained hyperchromatic small nuclei with scant cytoplasm indicating small cell NEC [13]. Histological examination also revealed some islands of squamous epithelium, esophageal glands beneath the columnar epithelium, and double-layered muscularis mucosae, indicating BE near the neoplastic lesion (Fig. 4). Immunohistochemically, the adenocarcinoma cells were negative for chromogranin A and synaptophysin, whereas the round-shaped carcinoma cells were diffusely positive for synaptophysin but negative for chromogranin A and p40. The Ki67 labeling index was $50 \%$ (Fig. 5). Based on these findings, a diagnosis of MANEC arising in BE was made. No metastasis of the carcinoma cells into resected regional lymph nodes was detected. The final pathological stage was T1 N0 M0 stage I according to the seventh edition of the Union for International Cancer Control classification.

The postoperative course was uneventful. The patient was discharged on postoperative day 19 and has been followed carefully without any adjuvant chemotherapy and no evidence of tumor recurrence 4 months after surgical resection.

\section{Discussion}

The 2010 WHO classification categorizes NETs into grade 1 and 2 NETs, neuroendocrine carcinoma (NEC), MANEC, and hyperplastic and preneoplastic lesion [2]. In this classification, grade 1 NETs (mitotic count $<2$ per 10 high-power fields [HPFs]), grade 2 NETs (mitotic count 2-20 per $10 \mathrm{HPFs}$ and/or Ki67 index >20\%), NEC (mitotic count $>20$ per $10 \mathrm{HPFs}$ and/or Ki67 index $>20 \%$ ) , and MANEC is defined as neoplasms comprised of both adenocarcinoma and NEC components in at least $30 \%$ of the tumor [2]. The tumor architecture is the most important diagnostic feature for MANEC, which is then confirmed by immunohistochemical findings such as chromogranin A, synaptophysin, CD56, and neuronspecific enolase expression [14]. Chromogranin A and
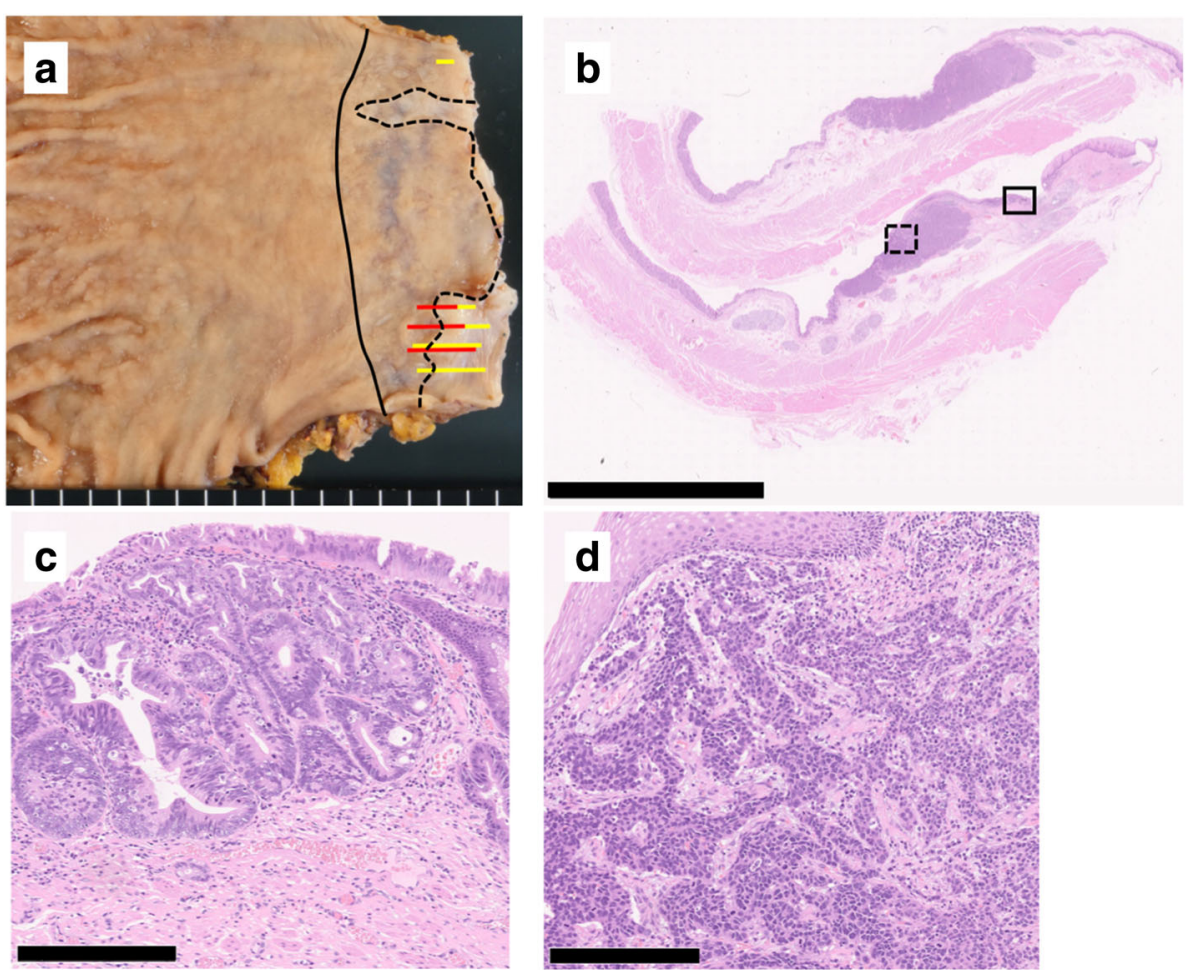

Fig. 3 Histological findings of MANEC. Macroscopically, a type 0-lla + IIc lesion measuring $25 \times 10 \mathrm{~mm}$ was detected in the esophagogastric junction. The black solid line indicates the esophagogastric junction, the black dotted line the squamocolumnar junction, the yellow line the adenocarcinoma component, and the red line the NEC component (a). A loupe image of the lesion is shown (b, scale bar $10 \mathrm{~nm}$ ). The solid rectangle indicates well differentiated adenocarcinoma (c scale bar $250 \mu \mathrm{m}$ ), and the dotted rectangle indicates an area of proliferation of roundshaped carcinoma cells with hyperchromatic nuclei and scant cytoplasm in a nested pattern, indicative of small cell NEC (d scale bar $250 \mu \mathrm{m}$ ) 

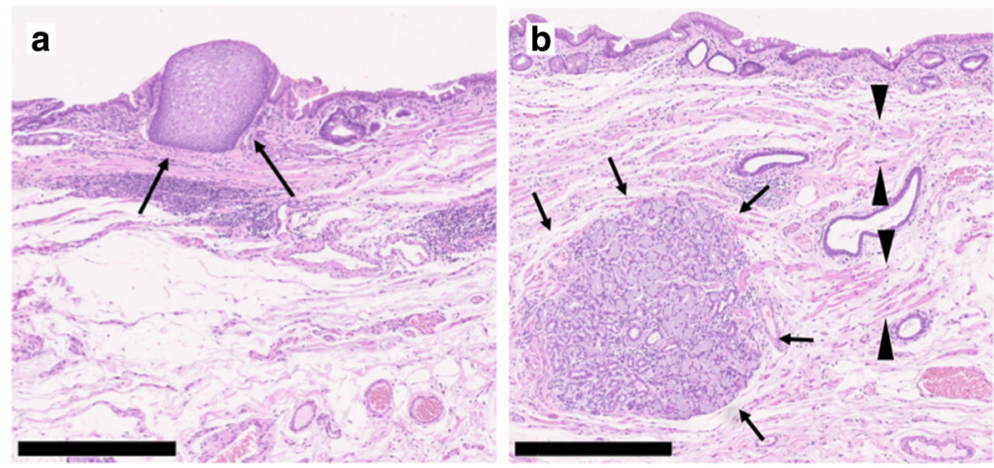

Fig. 4 Histological findings of Barrett's esophagus. BE was recognized histologically. Some islands of squamous epithelium (a, arrow), esophageal glands beneath the columnar epithelium (b, arrow), and double-layered muscularis mucosae (b, arrow head) were observed. All scale bars— 500 um

synaptophysin expression is seen in 69.1 and $90.2 \%$, respectively, of gastroenteropancreatic neuroendocrine neoplasms [15]. In the present case, almost equal proportions of the two components (adenocarcinoma and NEC) were confirmed. Immunohistochemically, the NEC component was positive for synaptophysin but negative for chromogranin A and p40. The Ki67 index was 50\%.

La Rosa et al. categorized mixed exocrine-neuroendocrine neoplasms of the gastrointestinal tract into three subgroups: high-grade malignant neoplasms composed of mixed adenoma/adenocarcinoma and NEC, intermediate-grade malignant neoplasms composed of adenocarcinoma and grade $1 / 2$ NET or amphicrine carcinoma, and mixed adenoneuroendocrine tumor composed of adenoma and NET [16]. According to this classification [16], our case fit the criteria of high-grade malignant MANEC.

$\mathrm{BE}$ is a precancerous condition in the development of esophageal adenocarcinoma, and it increases the risk of cancer by 11-fold [17]. Barrett's mucosa exhibits the three pathological characteristics mentioned above [7]. In this case, some islands of squamous epithelium, esophageal glands beneath the columnar epithelium, and double-layered muscularis mucosae were confirmed histologically. Based on these features, MANEC arising in $\mathrm{BE}$ was diagnosed.

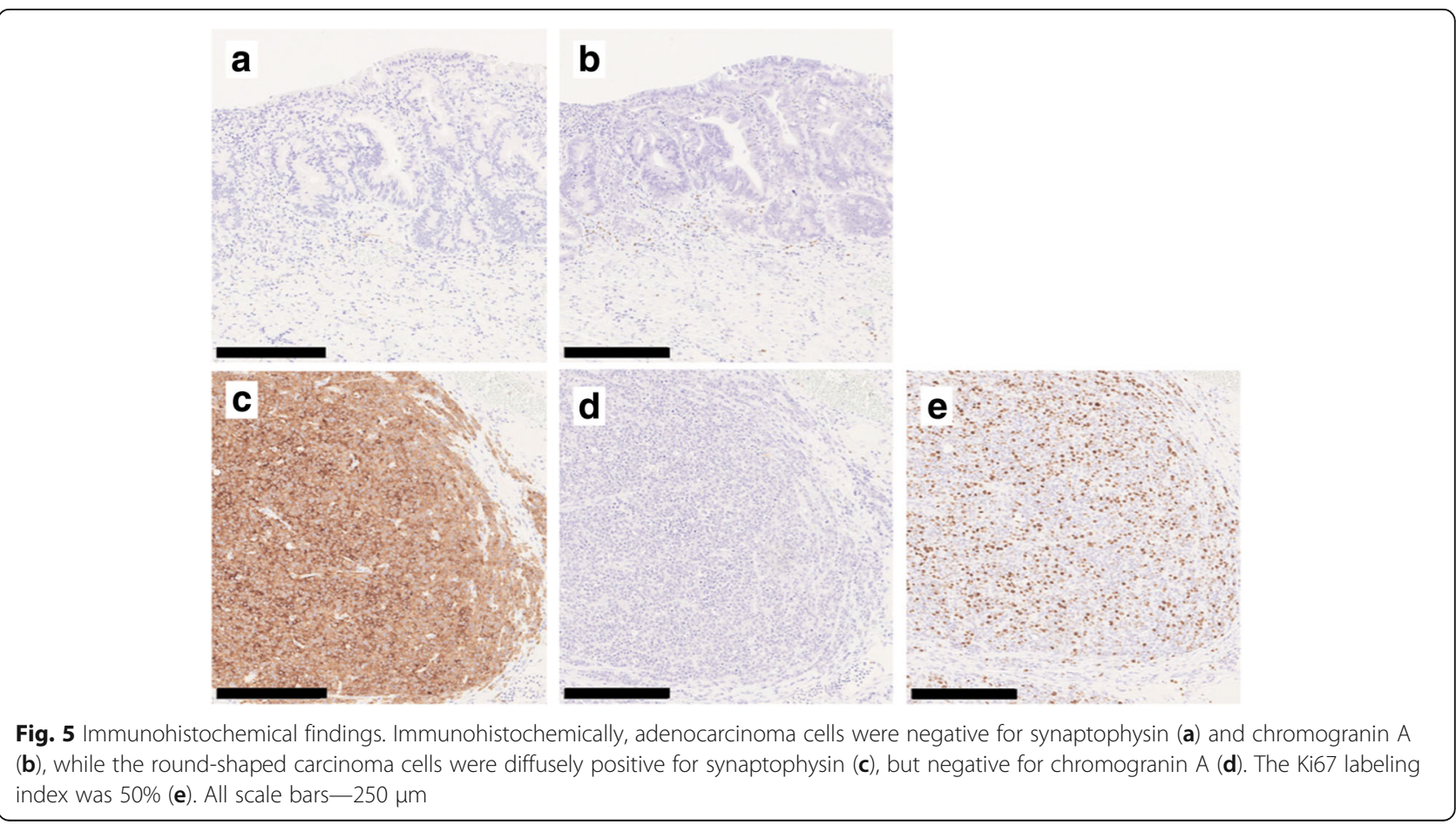


In the literature published to date, eight MANEC cases, including our case of MANEC located in the esophagus or esophagogastric junction, have been reported [3, 10, 18-21]. The clinicopathological features of the eight cases are shown in Table 1. Seven patients were male, and one patient was female. The mean age of the patients was 64 years (range, 57-70 years). The mean size of the tumors was $5.0 \mathrm{~cm}$ (range, 1.7-9.7 cm). Four cases developed in the esophagogastric junction and the other four in the esophagus. Seven cases were resected surgically, and one case with limited invasion to the submucosa was treated by endoscopic submucosal dissection. Lymph node metastases were observed in five cases. MANEC in BE was reported in only one case [10].

Regarding the origin of esophageal NETs, Merkel cells and stem cells are reported candidates [22, 23]. Egashira et al. showed positive staining for CK20, a marker of Merkel cells, in $14.3 \%$ of esophageal MANECs and suggested c-kit and p53 to be potential markers of the origin of NEC cells [22]. On the other hand, it was suggested that gastric NECs arise from adenocarcinomas rather than from non-neoplastic neuroendocrine cells [24]. If the origin of the tumor of our case was Merkel cells, the tumor would not be expected to exhibit adenocarcinoma differentiation but to exhibit squamous cell carcinoma differentiation, so in the present case, the tumor might have originated from esophageal adenocarcinoma or stem cells rather than Merkel cells. It is suggested that the $\mathrm{BE}$-esophageal adenocarcinoma-MANEC sequence is a potential mechanism in the pathway of MANEC carcinogenesis.
The specific and optimal treatment for MANEC in the esophagus is unknown due to the number of esophageal MANEC cases reported. According to previous reports, surgical treatment with regional lymph node dissection may be a treatment strategy for localized esophageal MANEC. Because the efficacy of lymph node dissection has not been demonstrated, further accumulation of cases is required. Adjuvant chemotherapy can be considered after resection, but there is no sufficient evidence [20]. While surgery may be the treatment of choice according to the WHO [2], multidisciplinary modalities can improve the prognosis of esophageal NEC even for resectable limited diseases [25]. The chemotherapy regimen administered for esophageal NEC is the same as that for small cell lung cancer, consisting of cisplatin, etoposide (VP-16), and irinotecan (CPT-11) [26].

Patients with mixed NEC in the esophagus (NEC plus adenocarcinoma or squamous cell carcinoma components) are more likely to be diagnosed at an earlier stage, and they showed a significantly longer survival, compared with patients with pure NEC (median survival, 28 vs. 15 months) [27]. The prognosis of high-grade MANEC was reported to depend on tumor stage and type [16].

\section{Conclusions}

We have demonstrated a very rare case of MANEC developing in $\mathrm{BE}$. $\mathrm{BE}$ can be the origin of esophageal MANEC as well as adenocarcinoma. The clinical and prognostic features of MANEC in BE are still unclear. Further studies are necessary to determine the optimal management strategy for esophageal or esophagogastric MANEC.

Table 1 Previously reported cases of esophageal or esophagogastric MANEC

\begin{tabular}{|c|c|c|c|c|c|c|c|c|c|c|c|}
\hline Case & Age & Sex & Location & Treatment & $\begin{array}{l}\text { Tumor } \\
\text { size }(\mathrm{cm})\end{array}$ & $\begin{array}{l}\text { Tumor } \\
\text { depth }\end{array}$ & $\begin{array}{l}\mathrm{LN} \\
\text { metastasis }\end{array}$ & $\begin{array}{l}\text { Adjuvant } \\
\text { chemotherapy }\end{array}$ & Recurrence & Prognosis & Author, year \\
\hline 1 & 64 & Male & Ut & Surgery & 1.7 & $\mathrm{T1}$ & No & None & None & Alive (16 months) & Kitajima, 2013 \\
\hline 2 & 63 & Male & EGJ & Surgery & 9.7 & T3 & N2 & $\begin{array}{l}\text { NAC } \\
\text { (CDDP + CPT-11), } \\
\text { adjuvant } \\
(\mathrm{S}-1+\text { CDDP) }\end{array}$ & None & Alive (24 months) & Nakai, 2013 \\
\hline 3 & 68 & Male & EGJ & ESD & ND & T1 & ND & ND & ND & ND & Veits, 2013 \\
\hline 4 & 68 & Male & $\mathrm{Lt}$ & Surgery & 9.5 & $\mathrm{~T} 4$ & Positive & ND & ND & ND & Kadhim, 2016 \\
\hline 5 & 57 & Male & EGJ & Surgery & ND & T3 & N3 & $\begin{array}{l}\text { Chemoradiation } \\
\text { (details ND) }\end{array}$ & None & Alive (8 months) & $\begin{array}{l}\text { Juanmartinena, } \\
2017\end{array}$ \\
\hline 6 & 64 & Female & Mt & Surgery & 4.0 & $\mathrm{~T} 2$ & N1 & $\begin{array}{l}\text { Platinum } \\
\text { and VP-16 }\end{array}$ & $\begin{array}{l}\text { Supraclavicular } \\
\text { lymph nodes } \\
\text { and liver } \\
\text { (4 months) }\end{array}$ & Dead (8 months) & Yuan, 2017 \\
\hline 7 & 62 & Male & Mt & Surgery & 6.0 & $\mathrm{~T} 2$ & N2 & $\begin{array}{l}\text { Platinum } \\
\text { and VP-16 }\end{array}$ & $\begin{array}{l}\text { Pleural effusion } \\
\text { ( } 2 \text { months) }\end{array}$ & $\begin{array}{l}\text { Dead } \\
\text { (19 months) }\end{array}$ & Yuan, 2017 \\
\hline Our case & 70 & Male & EGJ & Surgery & 2.5 & T1 & NO & None & None & Alive (4 months) & \\
\hline
\end{tabular}

Mt middle esophagus, EGJ esophagogastric junction, $L t$ lower esophagus, Ut upper esophagus, ESD endoscopic submucosal dissection, NAC neoadjuvant chemotherapy, CDDP cisplatin, VP-16 etoposide, ND not described 


\section{Abbreviations}

BE: Barrett's esophagus; HPF: High-power field; MANEC: Mixed adenoneuroendocrine carcinoma; NEC: Neuroendocrine carcinoma; NET: Neuroendocrine tumor; WHO: World Health Organization

\section{Availability of data and materials}

Data sharing is not applicable to this article, as no datasets were generated or analyzed during the current study.

\section{Authors' contributions}

TK and HS conceived the case presentation and drafted the manuscript. KE, SK, DT, KK, RN, NK, KA, and YN participated in the treatment of the patient. MF determined the pathological diagnosis of the patient. EO, YO, and YM revised the article. All authors read and approved the final manuscript.

\section{Ethics approval and consent to participate}

The present study was conducted in accordance with the ethical standards of our institution.

\section{Consent for publication}

Written informed consent was obtained from the patient for publication of this case report and any accompanying images.

\section{Competing interests}

The authors declare that they have no competing interests.

\section{Publisher's Note}

Springer Nature remains neutral with regard to jurisdictional claims in published maps and institutional affiliations.

\section{Author details}

${ }^{1}$ Department of Surgery and Science, Graduate School of Medical Sciences, Kyushu University, 3-1-1 Maidashi, Higashi-ku, Fukuoka 812-8582, Japan. ${ }^{2}$ Department of Anatomic Pathology, Pathological Sciences, Graduate School of Medical Sciences, Kyushu University, Fukuoka, Japan.

Received: 22 February 2018 Accepted: 30 April 2018

\section{Published online: 08 May 2018}

References

1. Kunz PL. Carcinoid and neuroendocrine tumors: building on success. J Clin Oncol. 2015:33(16):1855-63.

2. Bosman FT, Carneiro F, Hruban RH, Theise ND. WHO classification of tumours of the digestive system. 4th ed. Geneva: World Health Organization; 2010. https://www.cabdirect.org/cabdirect/abstract/ 20113051318

3. Kadhim MM, Jespersen ML, Pilegaard HK, Nordsmark M, Villadsen GE. Mixed adenoneuroendocrine carcinoma is a rare but important tumour found in the oesophagus. Case Rep Gastrointest Med. 2016;2016:9542687.

4. Yamauchi H, Sakurai S, Nakazawa N, Yoshida T, Tabe Y, Saitoh K, et al. A case of mixed adenoneuroendocrine carcinoma of the stomach with focal intestinal metaplasia and hypergastrinemia. Int Surg. 2015;100(3):562-7.

5. Kwok CM. Mixed adenoneuroendocrine carcinoma of the stomach. Case Rep Gastroenterol. 2015;9(2):241-5.

6. Ito H, Kudo A, Matsumura S, Ban D, Irie T, Ochiai T, et al. Mixed adenoneuroendocrine carcinoma of the colon progressed rapidly after hepatic rupture: report of a case. Int Surg. 2014:99(1):40-4.

7. Kuwano H, Nishimura Y, Oyama T, Kato H, Kitagawa Y, Kusano M, et al. Guidelines for diagnosis and treatment of carcinoma of the esophagus April 2012 edited by the Japan Esophageal Society. Esophagus. 2015;12:1-30.

8. Bhat S, Coleman HG, Yousef F, Johnston BT, McManus DT, Gavin AT, et al. Risk of malignant progression in Barrett's esophagus patients: results from a large population-based study. J Natl Cancer Inst. 2011;103(13):1049-57.

9. Gindea C, Birla R, Hoara P, Caragui A, Constantinoiu S. Barrett esophagus: history, definition and etiopathogeny. J Med Life. 2014;7(Spec No. 3):23-30.

10. Veits L, Lang-Schwarz C, Volkholz H, Falkeis C, Vieth M, Schulz H. Mixed adenoneuroendocrine carcinoma (MANEC) of the esophagogastric junction predominantly consisting of poorly differentiated neuroendocrine carcinoma. Endoscopy. 2013;45(Suppl 2 UCTN):E16-7.

11. Hori M, Matsuda T, Shibata A, Katanoda K, Sobue T, Nishimoto H. Cancer incidence and incidence rates in Japan in 2009: a study of 32 population- based cancer registries for the Monitoring of cancer Incidence in Japan (MCIJ) project. Jpn J Clin Oncol. 2015:45(9):884-91.

12. Tachimori $Y$, Ozawa S, Numasaki H, Ishihara R, Matsubara H, Muro K, et al. Comprehensive registry of esophageal cancer in Japan, 2010. Esophagus. 2017;14(3):189-214.

13. Huang $Q$, Wu H, Nie L, Shi J, Lebenthal A, Chen J, et al. Primary high-grade neuroendocrine carcinoma of the esophagus: a clinicopathologic and immunohistochemical study of 42 resection cases. Am J Surg Pathol. 2013; 37(4):467-83.

14. Gurzu S, Kadar Z, Bara T, Bara T Jr, Tamasi A, Azamfirei L, et al. Mixed adenoneuroendocrine carcinoma of gastrointestinal tract: report of two cases. World J Gastroenterol. 2015;21(4):1329-33.

15. Wang $Y H$, Lin $Y$, Xue L, Wang JH, Chen MH, Chen J. Relationship between clinical characteristics and survival of gastroenteropancreatic neuroendocrine neoplasms: a single-institution analysis (1995-2012) in South China. BMC Endocr Disord. 2012:12:30.

16. La Rosa S, Marando A, Sessa F, Capella C. Mixed adenoneuroendocrine carcinomas (MANECS) of the gastrointestinal tract: an update. Cancers (Basel). 2012;4(1):11-30.

17. Chandra S, Gorospe EC, Leggett CL, Wang KK. Barrett's esophagus in 2012 updates in pathogenesis, treatment, and surveillance. Curr Gastroenterol Rep. 2013:15(5):322.

18. Kitajima T, Kaida S, Lee S, Haruta S, Shinohara H, Ueno M, et al. Mixed adeno(neuro)endocrine carcinoma arising from the ectopic gastric mucosa of the upper thoracic esophagus. World J Surg Oncol. 2013;11:218.

19. Nakai M, Kawasaki H, Wajima N, Kimura A, Nakayama Y, Muroya T, et al. A case of mixed adenoneuroendocrine carcinoma of the esophagogastric junction treated with neoadjuvant chemotherapy. Gan To Kagaku Ryoho. 2013:40(12):2301-3.

20. Juanmartinena JF, Fernandez-Urien I, Cordoba A, Miranda C, Borda A. Mixed adenoneuroendocrine carcinoma (MANEC) of the gastroesophageal junction: a case report and review of the literature. Rev Esp Enferm Dig. 2017:109(2):160-2.

21. Yuan W, Liu Z, Lei W, Sun L, Yang H, Wang Y, et al. Mutation landscape and intra-tumor heterogeneity of two MANECs of the esophagus revealed by multi-region sequencing. Oncotarget. 2017;8(41):69610-21.

22. Egashira A, Morita M, Kumagai R, Taguchi KI, Ueda M, Yamaguchi S, et al. Neuroendocrine carcinoma of the esophagus: clinicopathological and immunohistochemical features of 14 cases. PLoS One. 2017;12(3):e0173501.

23. Harmse $\mathrm{J}$, Carey FA, Baird AR, Craig SR, Christie KN, Hopwood D, et al. Merkel cells in the human oesophagus. J Pathol. 1999;189(2):176-9.

24. Ishida M, Sekine S, Fukagawa T, Ohashi M, Morita S, Taniguchi H, et al, Neuroendocrine carcinoma of the stomach: morphologic and immunohistochemical characteristics and prognosis. Am J Surg Pathol. 2013;37(7):949-59.

25. Hou X, Wei JC, Wu JX, Wang X, Fu JH, Lin P, et al. Multidisciplinary modalities achieve encouraging long-term survival in resectable limited disease esophageal small cell carcinoma. PLoS One. 2013;8(7):e69259.

26. Takeoka T, Hirao M, Fujitani K, Yamamoto K, Asaoka T, Ikenaga M, et al. A case of neuroendocrine cell carcinoma of the esophagus with lung metastases successfully treated with CPT-11/CDDP. Gan To Kagaku Ryoho. 2013;40(12):2121-3.

27. Maru DM, Khurana H, Rashid A, Correa AM, Anandasabapathy S, Krishnan S, et al. Retrospective study of clinicopathologic features and prognosis of high-grade neuroendocrine carcinoma of the esophagus. Am J Surg Pathol. 2008;32(9):1404-11. 